\title{
A method for tsunami risk assessment: a case study for Kamakura, Japan
}

\author{
Non Okumura ${ }^{1} \cdot$ Sebastiaan N. Jonkman $^{1} \cdot$ Miguel Esteban $^{2} \cdot$ \\ Bas Hofland $^{1} \cdot$ Tomoya Shibayama $^{3}$
}

\begin{abstract}
This paper presents a methodology for tsunami risk assessment, which was applied to a case study in Kamakura, Japan. This methodology was developed in order to evaluate the effectiveness of a risk-reducing system against such hazards, also aiming to demonstrate that a risk assessment is possible for these episodic events. The tsunami risk assessment follows these general steps: (1) determination of the probability of flooding, (2) calculation of flood scenarios, (3) assessment of the consequences and (4) integration into a risk number or graph. The probability of flooding was approximated based on the data provided by local institutes, and the flood scenarios were modeled in 1D using the Simulating WAves till SHore model. Results showed that a tsunami in Kamakura can result in thousands of casualties. Interventions such as improvements in evacuation systems, which would directly reduce the number of casualties, would have a large influence in risk reduction. Although this method has its limits and constraints, it illustrates the value it can add to existing tsunami risk management in Japan.
\end{abstract}

\footnotetext{
Non Okumura

nonjapan@gmail.com

Sebastiaan N. Jonkman

s.n.jonkman@tudelft.nl

Miguel Esteban

esteban.fagan@gmail.com

Bas Hofland

b.hofland@tudelft.nl

Tomoya Shibayama

shibayama@waseda.jp
}

1 Faculty of Civil Engineering and Geosciences, Delft University of Technology, Stevinweg 1, 2628 CN Delft, The Netherlands

2 Graduate School of Frontier Sciences, University of Tokyo, 5-1-5 Kashiwanoha, Kashiwa City T277-8563, Japan

3 Department of Civil and Environmental Engineering, Waseda University, 3-4-1 Okubo, Shinjuku-ku, Tokyo 169-8555, Japan 
Keywords Tsunami risk assessment · Probability of flooding · Run-up and inundation scenarios $\cdot$ Kamakura $\cdot$ Risk-reduction interventions

\section{Introduction}

\subsection{General}

On March 11, 2011, the Tohoku Earthquake and Tsunami devastated a large section of the Tohoku coastline of northern Japan. This disaster resulted in 15,867 casualties, with 2909 still missing as of 2012 (Yamao et al. 2015).

The challenge of reducing the vulnerability of coastal areas to tsunamis has been widely recognized and discussed among the government and scientific community. Before the 2011, event flood protection measures were designed according to water levels set by cases of smaller earthquakes, where the tsunami heights were underestimated. In response to the 2011 tsunami, a broad categorization that separates tsunamis into two protection levels has been made. A Level 1 tsunami represents an event with a return period of several decades to $100+$ years, having lower inundation heights than a Level 2 event, which would have return periods between every few hundred to a few thousand years (potentially having inundation height of up to 20-30 m for the case of Tohoku). This concept also indicates that the function of coastal structures is to attempt to protect property against Level 1 events, whereas evacuation measures should be designed with Level 2 events in mind (Shibayama et al. 2013). Also, it is worth mentioning how there appears to be an empirical relationship between maximum tsunami height, minimum tsunami wave arrival time and potential risks to human life. Essentially, if residents have enough time to evacuate before defenses are overcome, they have a higher possibility of survival (Yamao et al. 2015).

A risk-based approach is applied in the flood management in the Netherlands (Jonkman et al. 2008; Jongejan and Maaskant 2015) and several other countries around the world, such as the UK (Hall et al. 2003), USA (IPET 2009) and China (Jiabi et al. 2013). The approach considers return periods of the hazard as well as their resulting damage and could offer some value to coastal risk managers in Japan. A study has already been made regarding a multilayer safety system in Tohoku, Japan, separately assessing the performance of each safety measure and their efficiency, and the implications of the use of multilayered safety in flood risk management (Tsimopoulou et al. 2012).

The risk-based approach to flood protection combines the knowledge on the probability of the occurrence of flood events with their consequences, such as damage to buildings and the loss of life. The approach aims to design and evaluate flood protections according to the risk, aiming to avoid the underestimation of hazards.

The objective of this article is to show how a general tsunami risk framework can be formulated and then proceed to quantitatively determine and evaluate this risk. The framework is derived from the flood risk assessment framework used in the Netherlands (Jonkman et al. 2008; Jongejan and Maaskant 2015; Jonkman and Schweckendiek 2015) and other countries for coastal and riverine flooding. The analyses carried out in this present research focus on the direct damage to buildings and potential loss of life, which are the most significant types of consequences. Results are presented for a case study that was made for Kamakura city, located $50 \mathrm{~km}$ southwest of Tokyo, which has residential areas and sightseeing spots, and would only have a small amount of time available for evacuation in the case of a nearshore tsunami. For this location, the risk reduction due to 
different interventions such as improvements in evacuation infrastructure and dike heightening is quantified, and the merits of the various interventions are discussed.

The article is structured as follows. The remainder of Sect. 1 gives the background information of the case study area of Kamakura in Japan. The methods used for the flood risk assessment are summarized in Sect. 2. Results are presented in Sect. 3. A discussion of the results is presented in Sect. 4, in which a preliminary risk-reduction solution is introduced, and the advantages of using a risk-based approach are discussed. Concluding remarks are given in Sect. 5.

\subsection{Case study in Kamakura, Japan}

Kamakura is a historical coastal city located in Sagami bay, and was at one time one of the two capitals of Japan, meaning that it is endowed with significant cultural heritage. The city has a population of 173,000 people (Kanagawa Prefectural Government 2016) and had up to 21.96 million tourists visiting it in 2014 (Kamakura City Office 2016), illustrating its importance to the country and the economy (Carlos-Arce et al. 2017). The coastline around the city is open and concave, which is expected to concentrate a tsunami's energy and likely result in high inundation heights shortly after a nearshore event. The North American Plate, Pacific Plate and the Philippine Sea Plate meet approximately $300 \mathrm{~km}$ away. There is also the Sagami Trough located just outside of the bay area, along with the Nankai Trough, which is also feared to have the potential to cause a large tsunami in the near future (Yamao et al. 2015).

Kamakura has experienced seven recorded tsunamis in its history, the most recent one resulting from the Great Kanto earthquake in 1923 (The Headquarters for Earthquake Research 2016). Unfortunately, most of the tsunami records do not offer precise data, as they took place too far in the past (Carlos-Arce et al. 2017). Existing protection measures in Kamakura include a road embankment (which would behave like a dike in the event of a tsunami) built along the coast to a level of around $+3 \mathrm{~m}$ (relative to MSL), designed against storm surge and wind waves, and emergency management measures, such as a hazard map illustrating the locations of evacuation centers (Kamakura City Office 2016; Carlos-Arce et al. 2017). Note that later evacuation centers will be neglected in the baseline case of this study.

\section{Methodology}

\subsection{General}

The methods for the tsunami risk assessment, which are derived from the framework used in the Netherlands, include four main steps: (1) determination of the probability of flooding, (2) calculation of flood scenarios, (3) assessment of the consequences and (4) integration into a risk number or graph. The risk is quantified based on the results from these steps. The risk reduction due to interventions is also quantified and evaluated. In theory, the estimation of the risk should be based on a fully probabilistic approach, which considers all the possible scenarios and their consequences. Due to limitations in time and resources, a simplified approach is usually chosen, where a limited number of flood scenarios are selected and elaborated upon. 
Elements of risk identification and analysis have been conducted all over the Japanese coasts by prefectural governments, and evacuation plans have been made by cities and wards as a part of risk management strategies (Central Disaster Management Council of Japan 2013). Tsunami models were run in 2D, and evacuation behavior was modeled with respect to tsunami arrival time and human behavior (Goto et al. 2012; Mas et al. 2012). However, complete risk assessments and evaluations including cost-benefit assessments were generally not performed. Tsunami risk assessments in the context of early warning and response have been studied in a case study in Indonesia (Strunz et al. 2011).

In this study, the authors essentially followed the methodology outlined above. One difference with risk management for the case of the Netherlands is that there is a certain low-lying area (polder) that is completely flooded after a certain water level is reached, while for the case of Japan (with coasts sloping upwards behind the beaches to hills and mountains) almost every tsunami will result in damage, the extent of which will vary according with the magnitude of the event. Each scenario refers to a different tsunami height along the coast, which is assumed to have one unique resulting pattern of flooding. The consequences of the selected flood scenarios have been analyzed by means of deterministic methods. By combining the probability of the flooding scenarios and their consequences, the risk can be estimated. These selected scenarios are assumed to represent the overall (probabilistic) distribution of events, although ideally all the flood scenarios need to be elaborated to estimate the overall risk. This approach, using selected scenarios, has its limitations, and it is clear that several improvements to it can be made. Nevertheless, even this relatively simplified model is expected to be able to provide preliminary estimates of the risk level.

In the present study, a one-dimensional (cross-sectional) approach is followed, which is judged to be sufficient to showcase the methodology proposed. A good indication of the risk can be obtained in this manner, while a more laborious two-dimensional (2D) approach would be needed for a more precise risk assessment. This $2 \mathrm{D}$ approach can be accomplished using the same modeling tools as used in the present research and should be the focus of future work. Below, the steps and main assumptions of the model are described in detail.

\subsection{Probability of flooding}

When assessing the probability of failure of a flood defense system, it is necessary to take into account the different failure mechanisms which can lead to flooding. This is especially true for the case of tsunamis, which can either overflow or breach defenses, requiring an assessment to be made of their strength against such events. For the case of Kamakura, it is assumed that overflowing will be the only failure mode, as the only flood defense system currently in place is the coastal road, which is unlikely to fail in the event of a tsunami [based on the performance of similar structures during the 2011 Tohoku event (Jayaratne et al. 2016; Mikami et al. 2012)]. If the risk of the flood defense failure was to be taken into account, the hydraulic load conditions and the resistance of the structure would also have to be considered.

For this study, the load is characterized by means of one stochastic variable (tsunami height), and the resistance by a deterministic variable (height of the flood defense). The inherent uncertainties, related to the occurrence of tsunami wave heights with time, have to be described by means of stochastic distributions. To do this, historical data on tsunami heights and their return periods are necessary. Kanagawa Prefectural Government (2016) modeled all known historical tsunamis in the last $\approx 550$ years (a total of 7 events) using 
the current bathymetry and topography of the area. Here, the incoming tsunami height is defined as the maximum water depth at the coastline before it is influenced by any of the protection measures.

Using this data, a regression analysis was conducted to approximate the return period of certain tsunami levels. The return period is inversely proportional to the probability of exceedance of tsunami height. The relationship between the approximated return period and the incoming wave heights for the different sections of the coast is then fitted with a distribution line chosen from the extreme value theory. The best-fit line is chosen based on different statistical tests and was selected to be the type 3 generalized extreme value (GEV) distribution. The distribution fitted to represent a representative tsunami level for the Kamakura coast is illustrated in Fig. 1. The fitted distribution will be used to describe the probability of flooding for the different scenarios in Sect. 2.3.

\subsection{Flood scenarios}

To assess the damage that can result from a tsunami, it is necessary to have an understanding of its hydraulic characteristics as it flows over land, such as inundation depth, flow velocity, run-up distance and arrival time. These were determined by different flood scenarios which were modeled in Simulating WAves till SHore (SWASH) (Zijlema et al. 2011). This efficient computer package is a shallow water flow model, with a pressure correction term that also enables a good representation of wave dispersion, wave-breaking behavior and flood-drying algorithms. A one-dimensional run-up model was created in SWASH, with the bathymetry of a chosen transect illustrated by the red line in Fig. 2. The transect was important for wave development in the 1D model. However, it is worth noting that the bathymetry in Kamakura bay and topography in the coastal area are rather uniform along the shore. The hydraulic characteristics were outputted along the entire computation grid for different time steps.

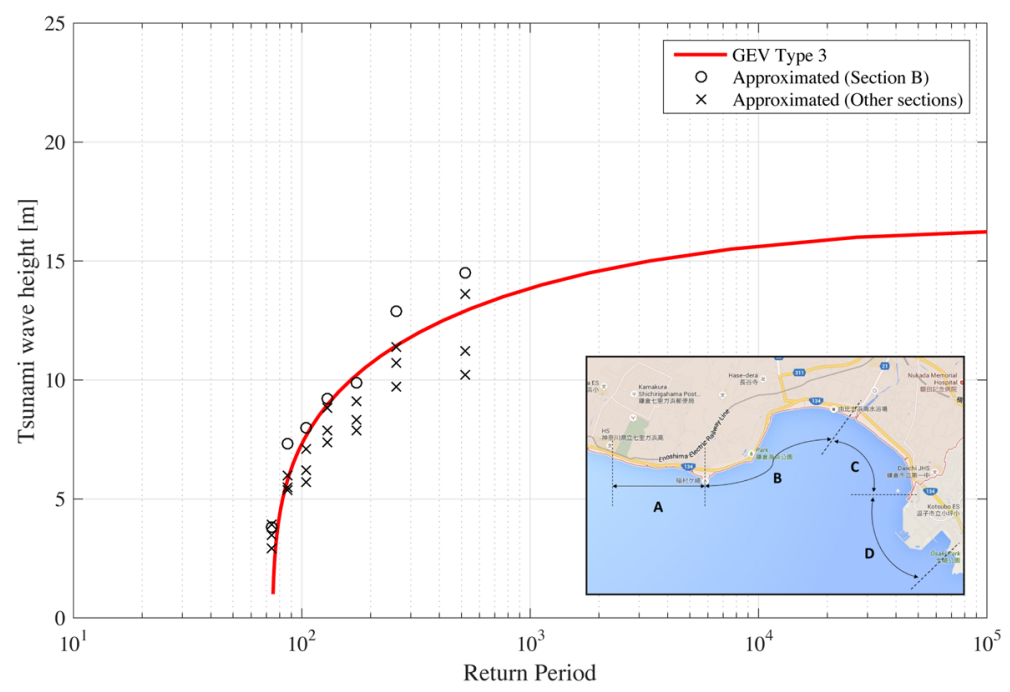

Fig. 1 Distribution curve of recalculated incoming tsunami heights for different sections of Kamakura coastline for seven historical tsunamis (Headquarter for Earthquake Research 2016). Coastline sections are defined on the map of Kamakura in the insert 

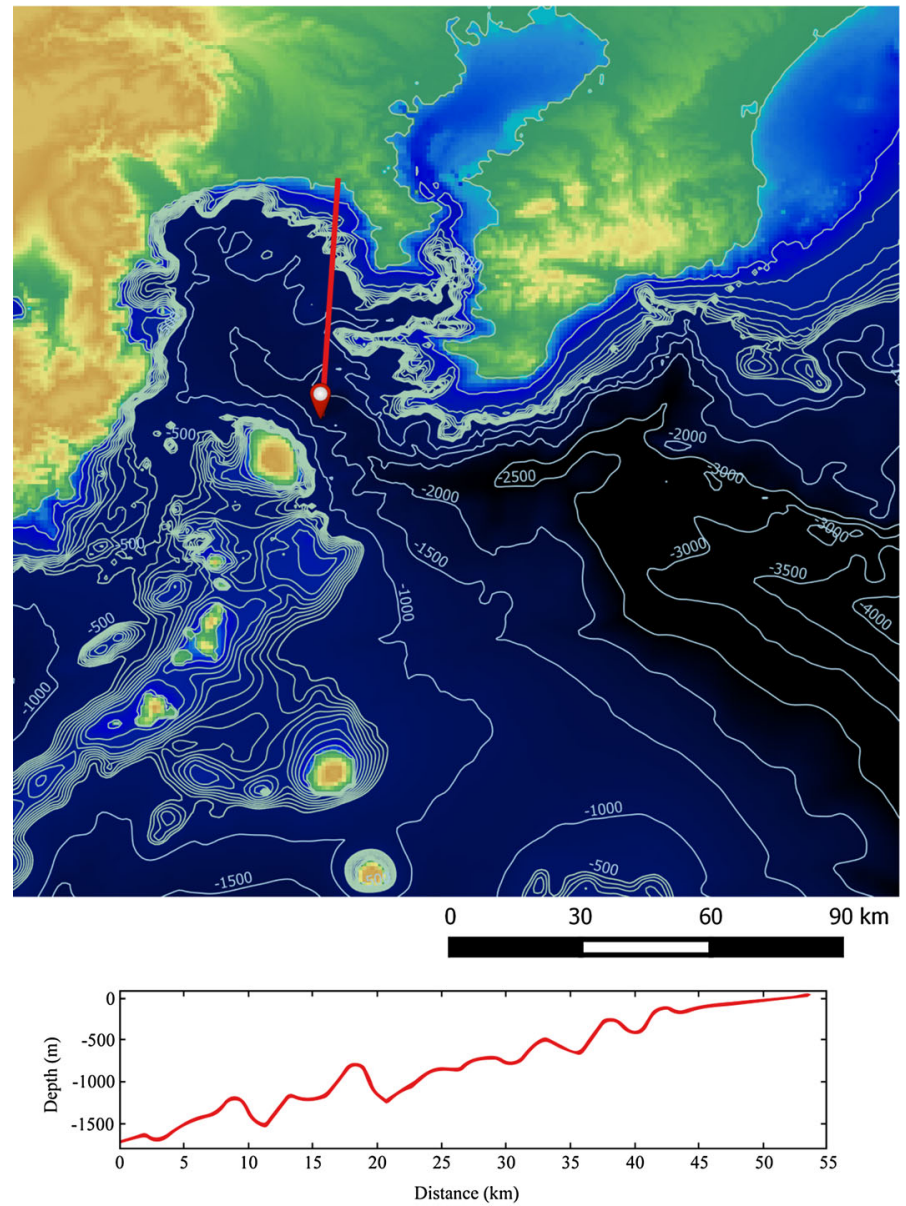

Fig. 2 Bathymetry map of coastal area near Kamakura, along with the chosen 1D transect (USGS 2016; GEBCO 2016)

Another important factor in the flood scenarios is the type of wave used to model a tsunami. Two types of waves, namely a solitary wave and (crest-leading) N-wave, were considered, as these are commonly used to model tsunamis. A simple calibration for the 1D flow model was conducted based on the 2011 tsunami event around Sendai to decide which wave type to use, and it was determined that the N-wave better captures the essential features observed there. This validation is illustrated in Fig. 3, which shows the measured envelope of inundations depths recorded in Sendai (Mori et al. 2011) and the inundation depths and run-ups for both types of waves, indicating that the $\mathrm{N}$-wave better captures the essential characteristics.

For Kamakura, which has a mild-sloping seabed similar to that at Sendai, a crest-leading $\mathrm{N}$-wave shape was applied to different incoming wave heights to create the flood scenarios. The flood scenarios will focus on tsunamis caused by the Sagami trough (the closest trough to Kamakura, and tsunamis caused by it are expected to have short warning times, which were considered to be the most dangerous case from the point of view of disaster risk 


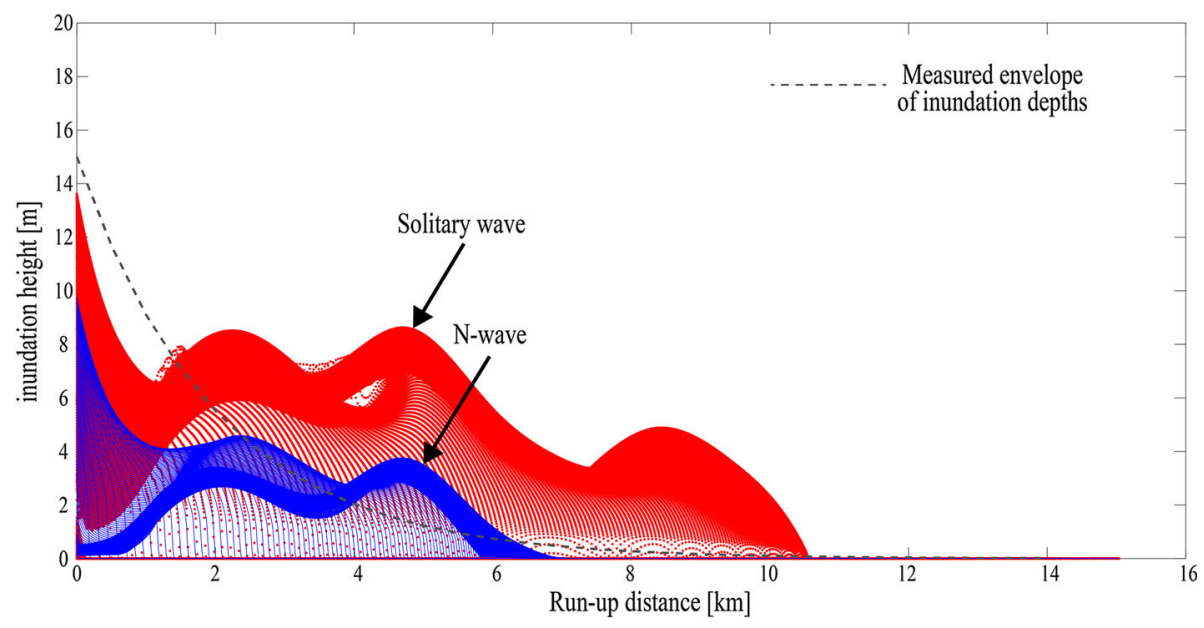

Fig. 3 Run-up distance and inundation depth of the solitary wave and N-wave SWASH simulations, together with the observed run-up distribution line around Sendai (Mori et al. 2011)

management in the city). The wave period is taken as constant, as the subduction failure areas that can cause a tsunami were assumed to be relatively constant in size. Since the same fault is chosen as the source of the tsunami, the length scale of the tsunami can also be assumed to be rather constant across different magnitudes. Moreover, the crest of the applied (crest-leading) $\mathrm{N}$-wave had a shorter duration than that of the solitary wave, so effectively the wave period was varied. Hence, if only the positive part of the $\mathrm{N}$-wave will contribute to the run-up, the wave period has been effectively varied. These flood scenarios are then analyzed to understand the different flood patterns and resulting consequences.

\subsection{Assessment of the consequences}

\subsubsection{General}

The consequences of a tsunami can be estimated based on the outputs of the flood scenarios from SWASH, and information regarding the spatial distribution of population density and land use patterns in Kamakura. These consequences were extrapolated from the 1D cross section to calculate the expected total damage to the exposed area of Kamakura and computed with a simplified version of existing damage functions for both loss of life and damage to buildings. The determining variable for the damage functions is the $d v$ (absolute value of the product of depth $d$ and velocity $v$ of the water) value, where the maximum $d v$ value in time is taken for each spatial unit in the computational grid to take into account the entire tsunami progression from landing to withdrawal. The proposed approach for estimating the loss of life and damage to buildings is briefly summarized in Sect. 2.5. Other damage categories such as business losses, number of injuries, the losses of historical values or indirect damage were not analyzed, which essentially makes the results of the present research conservative. 


\subsubsection{Loss of life}

The loss of life was determined following a methodology similar to that proposed in Jonkman and Penning-Rowsell (2008). Here, the method to estimate the loss of life has two main steps: estimating the exposed population and then estimating the mortality of that population. First, the exposed population for each flood scenario can be estimated by taking into account the arrival time of the tsunami and the time required for evacuation. The arrival time of the tsunami is determined from each of the flood scenarios simulated in SWASH. The time required for evacuation is estimated based on a simple evacuation model. Similar to the flood scenarios, the evacuation model is also represented in 1D, and thus, evacuation refers to a simple landward evacuation to higher grounds. For this study, the model assumes a uniform distribution of the population and only takes into account the local population and not the tourist population (again resulting in a conservative result). In the model, the time required for evacuation depends on the location of a given person along the cross section, the speed that person can evacuate at, and their evacuation behavior. The location of the people was taken from the computational grid of SWASH, and the speed of each individual took into account their age and the relative distribution of each population type (average adult, children and old/disabled) among the general population (Carey 2005).

Table 1 shows the percentages of people in each population type (Kanagawa Prefectural Government 2016) and the characteristic speed of each group. The inclusion of evacuation behavior was considered in the evacuation model, as it influences evacuation effectiveness, and this has been recognized as a big issue during the Tohoku earthquake in 2011 (Yun and Hamada 2012). The statistical values observed during the Tohoku event in 2011 will be used for Kamakura (presented as the initial condition in Table 2) to include evacuation behavior. These are split into three categories: those who evacuated immediately after receiving the tsunami warning (13\% of the population), those who evacuated with a delay (60\%), and those who did not evacuate at all (27\%) (Yun and Hamada 2012). Here, optimized communication is defined as a system which disseminates the tsunami warning efficiently, through the use of devices such as mobile phones, and it is thereby assumed to improve the evacuation behavior and effectiveness. This measure will be included as a risk-reduction intervention (see Sect. 2.5).

The criterion for safe evacuation is given as:

$$
t_{\text {evac }}=\frac{x_{\text {max }}-x_{0}}{c_{\text {evac }}}+t_{\text {delay }}
$$

Here, $t_{\mathrm{evac}}$ is the time it takes for a given person to evacuate from a location, $x_{\max }$ is the distance from the coast to safe grounds, $x_{0}$ is the distance from the coast to the location of a given person, $c_{\text {evac }}$ is the evacuation speed of a given person and $t_{\text {delay }}$ is the time delay to

Table 1 Age distribution, percentage of population and evacuation speed (Carey 2005; Kanagawa Prefectural Government 2016)

\begin{tabular}{llll}
\hline & Age distribution & Percentage of population & Evacuation speed $(\mathrm{m} / \mathrm{s})$ \\
\hline Children & $0-14$ & 12 & 1.20 \\
Average adults & $15-64$ & 56 & 1.38 \\
Old/Disabled & $>65$ & 32 & 1.00 \\
\hline
\end{tabular}


Table 2 Evacuation behavior fractions for the initial situation (Yun and Hamada 2012) and those after the expected optimized communication

\begin{tabular}{lll}
\hline $\begin{array}{l}\text { Evacuation } \\
\text { behavior }\end{array}$ & $\begin{array}{l}\text { Initial condition } \\
(\%)\end{array}$ & $\begin{array}{l}\text { Optimized communication } \\
(\%)\end{array}$ \\
\hline Immediate & 13 & 25 \\
Delayed & 60 & 65 \\
None & 27 & 10 \\
\hline
\end{tabular}

begin evacuation. The delay observed in the Tohoku event ranged from 5 to $60 \mathrm{~min}$. This was simplified and adjusted for the case of Kamakura and was given a deterministic value of $5 \mathrm{~min}$. This is approximately one fourth of the time available before the tsunami arrives. This simplified approach can be used to define which zones are safe and which parts of the population are exposed to the tsunami inundation. An example of the applied evacuation model is given in Fig. 4.

People who start evacuation in the pink zone are expected to be caught up by the tsunami. For example, a child who is located at the coast survives if he or she starts to evacuate immediately, though another child in the same location will be caught up by the tsunami if he or she waits $5 \mathrm{~min}$ to start evacuating.

Second, to estimate the number of casualties among the exposed population, a mortality function that takes into account the $d v$ criteria was also used, based on previous research on stability of people in flood flows (Jonkman and Penning-Rowsell 2008).

$$
F(d v)= \begin{cases}1, & \text { if } d v \geq 2 \mathrm{~m}^{2} / \mathrm{s} \\ 0.5, & \text { if } 0.5 \leq d v<2 \mathrm{~m}^{2} / \mathrm{s} \\ 0, & \text { if } d v<0.5 \mathrm{~m}^{2} / \mathrm{s}\end{cases}
$$

If the result of the damage function is 1 , mortality is assumed to be $100 \%$ for that given location (Jonkman and Penning-Rowsell 2008). The estimated mortality function is combined with the exposed population at a given location in time to approximate the number of casualties resulting from each of the flood scenarios. The exposed population in the possible inundation area is approximated to be 98,349 people from the size of the

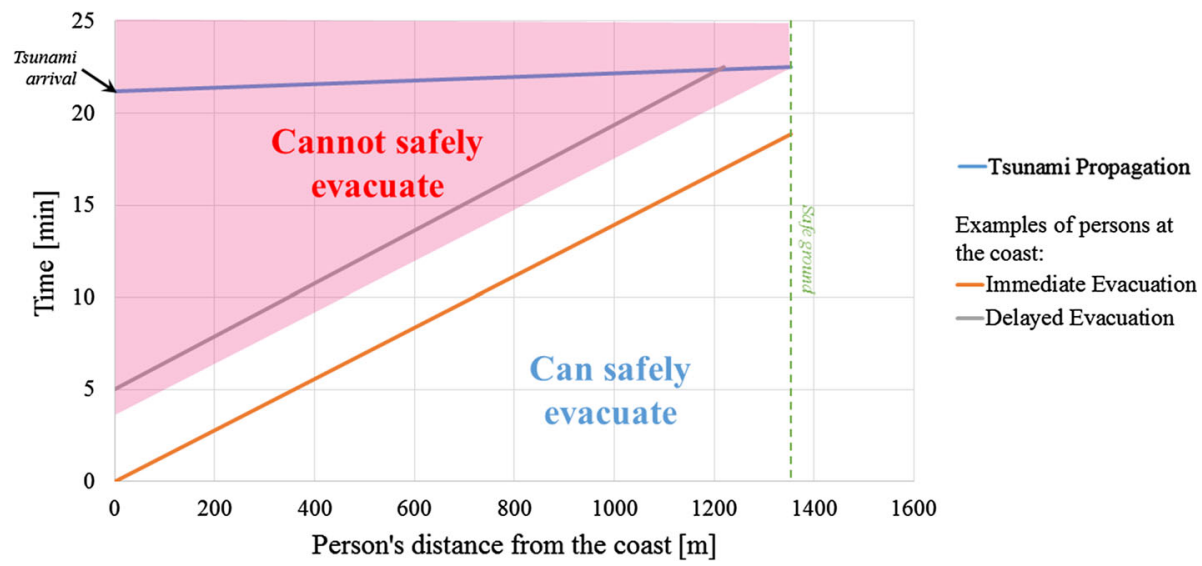

Fig. 4 Example of $x-t$ diagram for the age category of children $(1.2 \mathrm{~m} / \mathrm{s})$ for a $14-\mathrm{m}$ tsunami flood scenario 
SWASH computational grid, the length of the coast and the population density of Kamakura (Kanagawa Prefectural Government 2016).

To come to an economic assessment of the damages, this approach for estimating life loss can also be combined with the cost of human life, which is $€ 2.1$ million (¥226 million), after the value given by the Ministry of Land, Infrastructure, Transport and Tourism (2009) to evaluate civil projects.

\subsubsection{Damage to buildings}

The damage to buildings was determined by the methods proposed in Pistrika and Jonkman (2010). The method also uses a damage function that includes three different levels: "inundation damage," "partial damage" and "total destruction." The number of buildings exposed to flooding is directly determined from the run-up distance, and it is assumed that the buildings are uniformly distributed along the cross section. Similar to that of mortality, the damage function for buildings is also a function of the $d v$ values (Pistrika and Jonkman 2010). This damage function was developed for wooden houses in New Orleans, and is assumed to be applicable for Kamakura as 67\% of buildings are wooden (Kanagawa Prefectural Government 2016). The damage fraction $F$ expresses the fraction of the value of the building that is lost.

$$
F(d v)= \begin{cases}0.00, & \text { if } v=0 \cup d=0 \\ 0.50, & \text { if } 0<d v<3 \mathrm{~m}^{3} / \mathrm{s} \\ 0.75, & \text { if } 3 \leq d v<7 \mathrm{~m}^{3} / \mathrm{s} \\ 1.00, & \text { if } d v \geq 7 \mathrm{~m}^{3} / \mathrm{s}\end{cases}
$$

The jump from no damage to 50\% damage allows the inclusion of non-structural damage costs, such as the costs of goods and furniture inside a house. The cost of repairs is the product of the market value of a building and the percentage damage value. The market value of a building was offset as $€ 0.28$ million ( $¥ 35$ million), which is the average value of a house in Kamakura (Kamakura City Office 2016).

\subsection{Risk-reduction interventions}

Various interventions are available to reduce tsunami and flood risks, ranging from offshore breakwaters, coastal or inland defenses, construction of flood proof buildings and warning and evacuation systems. The types of risk-reduction interventions that can be attempted in a given area are influenced by coastal topographic characteristics and societal demands. For the case of Kamakura, there are some limitations to the possible interventions that can be envisaged. For example, the construction of an offshore breakwater in Kamakura would be very expensive due to the nearshore bathymetry having a steep profile, and the community and local economy highly rely on tourism, meaning that coastal aesthetics need to be protected. Spatial solutions also face land planning limitations, as the city is densely built. Given these circumstances, the authors chose to analyze only the types of interventions that were considered feasible in both economic and social acceptance terms, namely heightening the road dike, and the improvement in evacuation measures. Evacuation can be facilitated through the construction of vertical evacuation buildings which aim to shorten the evacuation distance and optimized communication which aims to improve the human evacuation behavior in case of a disaster (Carlos-Arce et al. 2017; Takabatake et al. 2017). 
Vertical evacuation proved extremely valuable during the Tohoku disaster in 2011 (Fraser et al. 2012). Due to an existing building code in Kamakura, buildings are limited to a height of $15 \mathrm{~m}$ (Kamakura City Office 2016). A reference evacuation building developed by Daiwa House (2015) requires the structure to be built in areas where the inundation depth is less than $5 \mathrm{~m}$. To meet these requirements for what is expected for a 1 in 1000 year tsunami, the vertical evacuation buildings were chosen to be built $960 \mathrm{~m}$ inland from the coast and assumed not to have a limit to the number of individuals they could accommodate-as illustrated in Fig. 5. The mountains are illustrated in the figure to show that in reality there are other evacuation areas or high grounds available for people. Existing evacuation buildings, as shown in the insert of Fig. 5, were not taken into account in this paper as the location of the building was also one of the factors to be tested for risk reduction. Optimized evacuation was also very effective during the 2011 tsunami in Minamisanriku (Fraser et al. 2012). By optimizing communication to disseminate a tsunami warning, the evacuation behavior is assumed to improve based on engineering judgement, as illustrated in Table 2.

\section{Results of risk quantification}

\subsection{Probability and consequence estimates}

A variety of different tsunami scenarios can cause flooding to Kamakura. Seven different tsunami levels with incoming wave heights of $6,8,11,12,13.5,14,14.5 \mathrm{~m}$ were modeled for the flood scenarios, together with different combinations of risk-reduction interventions.

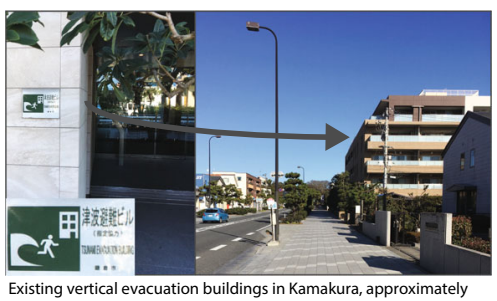

Existing vertical evacuation buildings in Kamakura, approximately 360 meters from the shore. (Picture taken in Dec 2016)

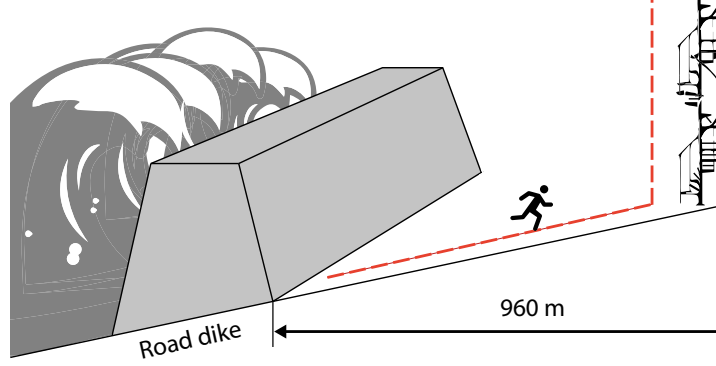

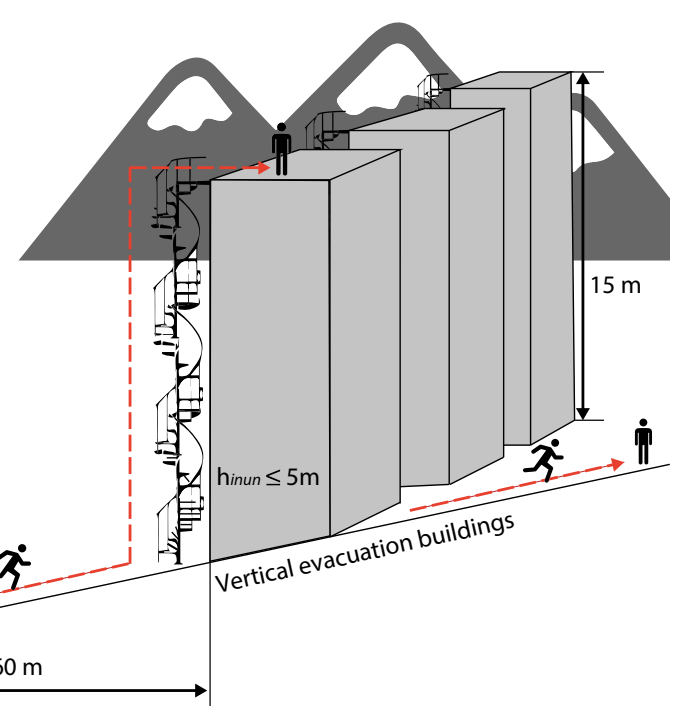

Fig. 5 Schematization of vertical evacuation buildings and their conditions 
The baseline situation (also shown in Fig. 7) illustrates the risk for the current situation, taking into account the influence of the existing protection measures (with the 3-m-high road dike). The risk-reduction interventions were then compared with the baseline situation to assess the reduction in the potential consequences.

The return periods for the seven tsunamis scenarios considered were obtained from the exceedance curve shown in Fig. 1, and the consequences derived from the flood scenarios presented in Table 3. The simulated arrival time, run-up distances and propagation speeds for the tsunami levels are presented in Fig. 6. For all scenarios, large parts of Kamakura would be affected. As all the tsunamis are simulated to originate from an earthquake along the Sagami trough, with increasing tsunami height the run-up distance becomes larger and arrival time decreases. The maximum run-up distance for the 1D run-up scenarios simulated in the present work is approximately $1.4 \mathrm{~km}$. This was compared with the maximum run-up distances measured in a 2D simulation modeled using the finite difference method, and a 3D simulation modeled using the finite volume method (Ishii 2017 (Bachelor Thesis, submitted); Takabatake et al. 2017). Both the 2D and 3D results estimated the maximum run-up distance to be $1.58 \mathrm{~km}$, showing how using a 1D model (as in the present case) does not result in a significant decrease in accuracy. The maximum run-up measured in the 1D model was also compared with the 2D tsunami model ran by the Central Disaster Management Council of Japan (2013). The maximum run-up was approximately 780-m inland for a Genroku-type tsunami with an incoming wave height of approximately $10 \mathrm{~m}$, which is in between the simulated tsunamis in this study, with wave heights of 8 and $11 \mathrm{~m}$ (see Fig. 6).

The economic damages were also assessed, including both the loss of life and building damage, which ranged from $€ 12.1$ to $€ 37.6$ billion for incoming tsunami heights from 6 to $14.5 \mathrm{~m}$, with over $90 \%$ of these total costs being the result of fatalities. The number of casualties ranged from 5280 to 16,232 people (corresponding to $5.4-16.5 \%$ of the exposed population). From these results, it is clear that in order to reduce the overall risk the number of casualties should be significantly reduced.

For the first intervention, the existing road dike of $3 \mathrm{~m}$ was heightened to four different heights: 4, 8, 12 and $16 \mathrm{~m}$. The results showed that the damage reduction from heightening the road dike is limited, i.e., the largest risk reduction is approximately $€ 15$ billion for a 16- $\mathrm{m}$ dike. There is a limit to the damage reduction because overflow occurs even with the construction of large road dikes, as the simulation model employed indicated that for the

Table 3 Calculated tsunami return periods and corresponding losses of life and financial losses in the housing sector

\begin{tabular}{lcclll}
\hline $\begin{array}{l}\text { Tsunami } \\
\text { level }(\mathrm{m})\end{array}$ & $\begin{array}{l}\text { Return period } \\
\text { (years) }\end{array}$ & $\begin{array}{l}\text { Expected casualties } \\
\text { [number of people }(\%)]\end{array}$ & $\begin{array}{l}\text { Loss of life } \\
(\mathrm{B} €)\end{array}$ & $\begin{array}{l}\text { Building } \\
\text { damage }(\mathrm{B} €)\end{array}$ & $\begin{array}{l}\text { Total } \\
\text { damage (B€) }\end{array}$ \\
\hline 6 & 88 & $5280(5.4)$ & 11.09 & 0.83 & 12.1 \\
8 & 110 & $7423(7.5)$ & 15.59 & 1.22 & 17.0 \\
11 & 221 & $10,245(10.4)$ & 21.52 & 1.72 & 23.2 \\
12 & 327 & $11,536(11.7)$ & 24.23 & 1.88 & 27.6 \\
13.5 & 761 & $12,348(12.6)$ & 25.93 & 1.95 & 28.7 \\
14 & 1124 & $15,168(15.4)$ & 31.85 & 2.19 & 34.7 \\
14.5 & 1809 & $16,232(16.5)$ & 34.09 & 2.29 & 37.6 \\
\hline
\end{tabular}




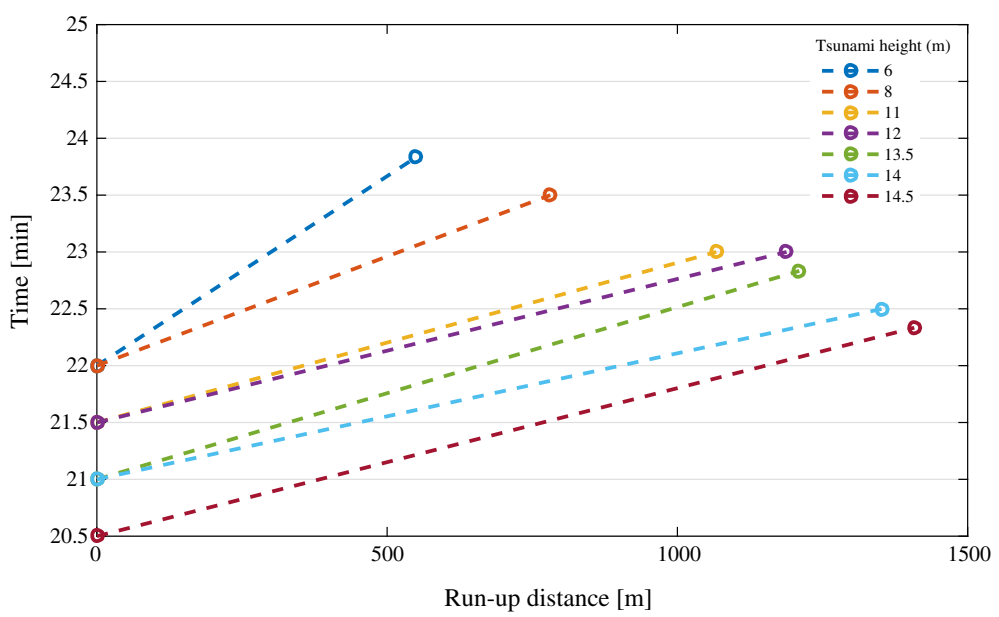

Fig. 6 Maximum run-up distances and arrival times of tsunamis of various magnitude or return period

case of an $\mathrm{N}$-wave the incoming tsunami bore is (partially) reflected by the tsunami wall (though it is not clear how accurately the model is able to reproduce the real tsunami in this case). Moreover, the dense population of Kamakura leads to large numbers of casualties even when the inundation area is small.

For the second intervention, two different types of evacuation improvements were shown to have different advantages. Vertical evacuation buildings were observed to be effective for large-scale tsunamis as the run-up distances are larger, illustrating their value to reduce casualties. Optimized communication reduced damage costs by half, and the number of casualties by half or more depending on the flood scenarios. There is a limit to the number of casualties which can be reduced in the evacuation model used in this study, as there is still $10 \%$ of the population who are assumed not to evacuate; thus, further reduction in casualties would require improvement in evacuation behavior.

\subsection{Risk quantification}

Based on the information regarding the probability and consequences, a cost-benefit analysis (CBA) can be conducted, and the individual and societal risk quantified. In the Netherlands, a CBA is used as a decision-making tool for flood management to determine which solution is the most efficient (Kind 2014). The analysis takes into consideration the flood risk and the cost of preventive measures. The individual risk, also known as local risk, is the probability of dying due to flooding of an average, unprotected person at the site under consideration (Jonkman and Schweckendiek 2015). The societal risk represents the relationship between the probability of failure due to an event and the number of fatalities expected from it. This relationship is known as the FN criterion (Vrijling and van Gelder 2002). The results of the CBA will be presented first, followed by the results of the individual and societal risk. 


\subsubsection{Cost-benefit analysis}

The conceptual model used to evaluate the CBA considers the total cost (TC) of the project over its lifetime as the sum of the investment $(I)$ and the risk $(R)$. In an optimal situation the solution involves the minimization of the TC,

$$
\mathrm{TC}=I+R, \quad \text { where } R=\sum \frac{P_{f} \cdot(L+D)}{r^{\prime}}
$$

The risk is computed from the probability of flooding $\left(\mathrm{P}_{\mathrm{f}}\right)$ and the costs of loss of life $(L)$ and damage to buildings $(D)$. Both the investment and risk is given in terms of net present value (NPV), where the interest rate $r^{\prime}$ is $2.5 \%$. This value was adjusted from the real interest rate in Japan to maximize the value of the project (de Neufville 1990). Investments aim to create a safer system and are compared with the reduction in the risk in the system. The investments for this study are the costs for heightening the dike and improving the evacuation system. Investments for the dike heightening include the initial costs, variable heightening costs and relocation costs (of houses due to widening of the dike). For evacuation improvements, the investments include the maintenance/operational costs for the early warning system, construction costs for the vertical evacuation building and costs of the optimized communication. A summary of these costs is given in Table 4 .

The results of the CBA can determine the optimal solution, i.e., the one that results in the lowest total cost. The annual total risk, which is the sum of the probability multiplied by its consequences, for the baseline (current) situation was $€ 257.5$ million, and the NPV risk was $€ 10.3$ billion.

The results illustrated in Fig. 7 show the relationship between the investment and the decrease in risk for each intervention, and Table 5 provides the cost-benefit ratios of some of the interventions. In Fig. 7, the vertical distance from the baseline to each point illustrates the monetary risk reduction in that intervention, i.e., optimized communication had a risk reduction of $€ 5.7$ billion. The risk reduction in vertical evacuation is shown to be low, as the present research assumes that $27 \%$ of the population will not evacuate. Thus, changes in evacuation behavior (indicated as optimized communication) are necessary if vertical evacuation buildings are to play a major role in safeguarding the lives of local residents. This is demonstrated by the lowest risk of the considered options being the combination of evacuation interventions, illustrated by the blue cross (also, cost-benefit ratio for improved evacuation is the largest, as shown in Table 5).

Table 4 Investment costs for different interventions

\begin{tabular}{llll}
\hline Measure & Variables & \multicolumn{2}{l}{ Value } \\
\hline Dike heightening & Initial costs & 48 & $\mathrm{M} € / \mathrm{km}$ \\
& Variable costs & 10 & $\mathrm{M} € / \mathrm{m} / \mathrm{km}$ \\
& Relocation & 1920 & $€ / \mathrm{m}^{2}$ \\
Evacuation improvement & Maintenance and operation costs for early warning system & 14.4 & $\mathrm{M} € /$ year \\
& Vertical evacuation costs & 3.3 & M€/year \\
& Opt. communication & 29.3 & M€/year \\
\hline
\end{tabular}




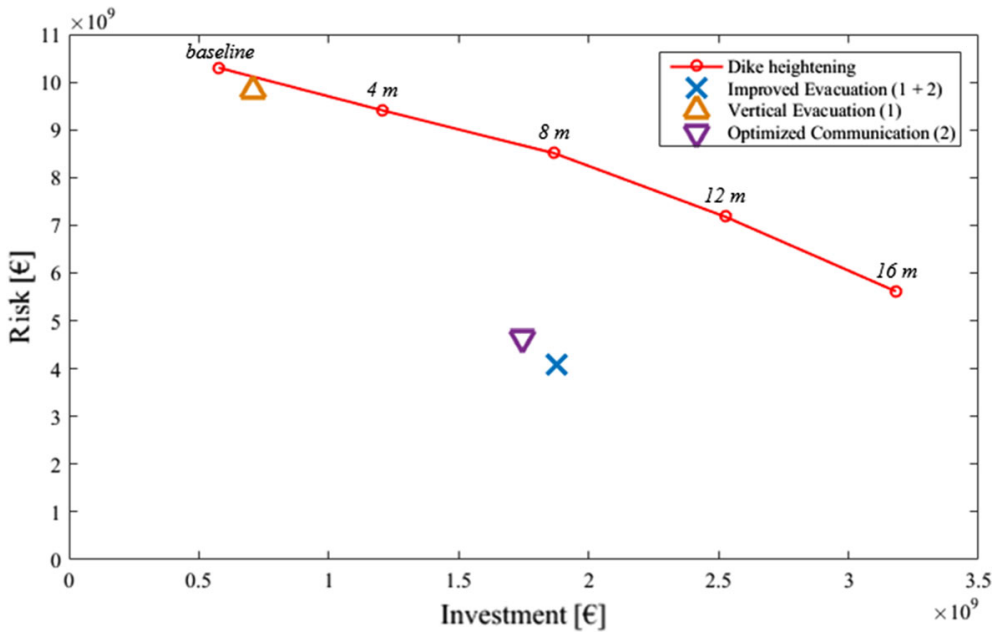

Fig. 7 Relationship between the risk and their investment of different risk-reduction interventions

Table 5 Costs and benefit-cost ratio for different interventions, compared to baseline situation

\begin{tabular}{lclrrl}
\hline & $\begin{array}{l}\text { Dike height } \\
(\mathrm{m})\end{array}$ & $\begin{array}{l}\text { Investment } \\
(\mathrm{B} €)\end{array}$ & Risk $(\mathrm{B} €)$ & $\begin{array}{l}\text { Total cost } \\
(\mathrm{B} €)\end{array}$ & $\begin{array}{l}\text { Benefit-cost } \\
\text { ratio }\end{array}$ \\
\hline Baseline situation & 3 & 0.58 & 10.3 & 10.88 & - \\
Dike heightening & 16 & 3.18 & 5.61 & 8.80 & 0.47 \\
Vertical evacuation (1) & 3 & 0.71 & 9.85 & 10.56 & 0.45 \\
Opt. communication (2) & 3 & 1.74 & 4.65 & 6.40 & 2.57 \\
Improved evacuation $(1+2)$ & 3 & 1.88 & 4.11 & 5.98 & 2.61 \\
\hline
\end{tabular}

\subsubsection{Individual and societal risk}

The concept of individual risk and societal risk is commonly used to assess the acceptable level of risk to life for flooding in the Netherlands (Jonkman et al. 2011) as an addition to the CBA when evaluating a flood defense system. It is important to note that acceptable risk levels for both individual and societal risk are not defined in Japan for tsunamis, but are computed in this study to present the existing risk levels for tsunami-prone areas.

The individual risk is computed with the following equation:

$$
\operatorname{IR}(x)=\sum P_{f} \times P_{d \mid f}(x)
$$

$P_{d \mid f}$ is the probability of death given a flood event and is dependent on the mortality zones, or simply a location $x$, which is defined as a function of the $d v$ values used when estimating the loss of life. The individual risk for the baseline situation is computed to be $2.44 \times 10^{3}$ per year for areas close to the shore, where the expected mortality is $100 \%$. The acceptable level of individual risk for areas in the Netherlands that are protected by flood defenses has been proposed to be $10^{-5}$ per year (Jonkman et al. 2011; Vrijling et al. 1998). 
The societal risk is concerned with the large-scale effects that a high-order event can have throughout the economic and social life of a country. The acceptable level of societal risk can be presented by the limit line. For flood risks in the Netherlands, a limit line has been proposed by Vrijling et al. (1998) called the "TAW line," taking into account country-specific accident statistics and accepted risks in other sectors. The limit line can be shifted to take into account differences in risk acceptance and perception between various sectors. For example, risk criteria (and thus limit lines) are stricter for chemical nuclear facilities than for flood protection systems in the Netherlands. Applications and scaling of the framework to other countries have been explored, i.e., Vietnam (Van Mai 2010). The results for Kamakura are illustrated in Fig. 8 along with the TAW line.

A given situation is considered safe when the curve lies within the limit line. Thus, Fig. 8 illustrates the high-risk levels tsunamis pose and the importance of defining different acceptable risk levels for different hazards. The FN curve for tsunamis is presented to demonstrate another method of defining safety levels.

\section{Discussion}

\subsection{General}

Results indicate that a tsunami in Kamakura can cause thousands of fatalities. The flood scenarios in this study are limited to Kamakura, but when considering the entire coastline of Sagami Bay, which includes multiple large cities, the consequence of such tsunami can be disastrous. For the scenarios simulated, the percentages of the estimated number of fatalities with respect to the exposed population are in line with the observed fatality proportions in the aftermath of the Tohoku event of 2011 (Yamao et al. 2015).

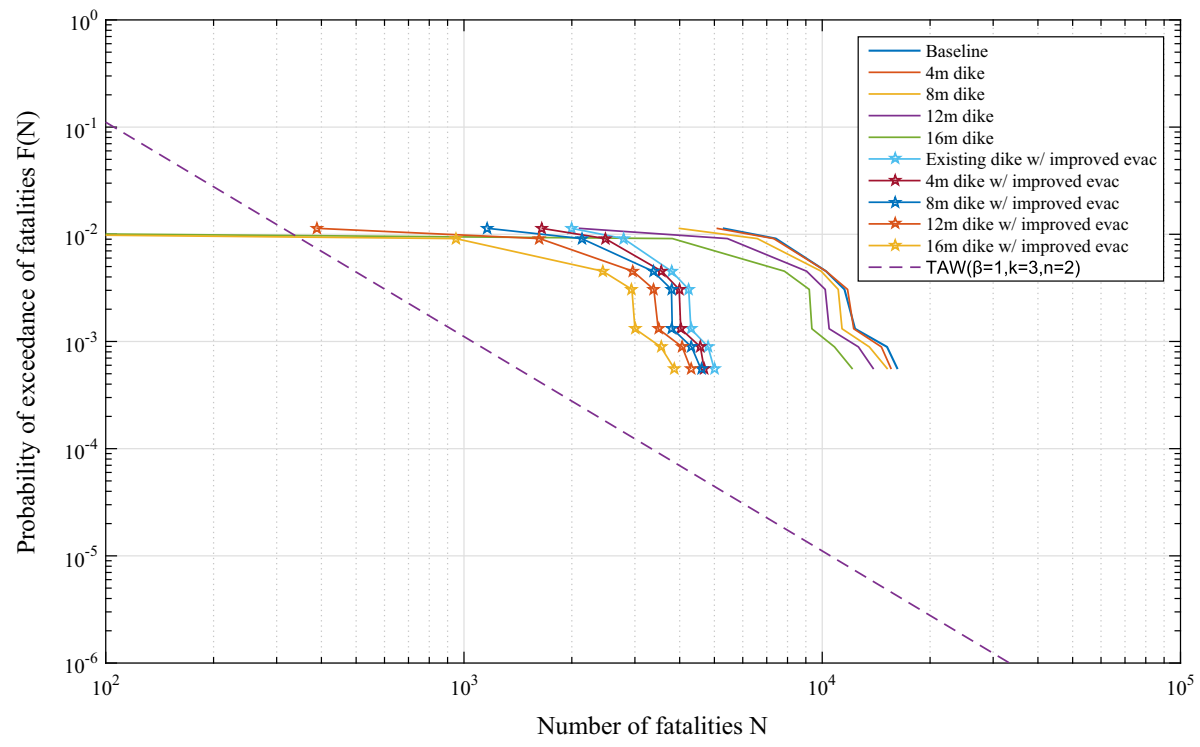

Fig. 8 FN curves for different tsunami scenarios along with the TAW line 
A large variation can be seen in the estimated number of casualties, depending on the scale of the tsunami. This is due to the large differences in the run-up distances, which are directly dependent on the size of the incoming wave height; the larger the incoming wave height, the larger the run-up distance. However, a more realistic estimation of casualties can be made by reducing the uncertainties which exist in the proposed simplified tsunami risk assessment. The evacuation model estimates the number of fatalities based on parameters such as evacuation speed, delay times and other factors which are given deterministic values. By using the probabilistic distributions for these parameters, a more realistic estimation of evacuation could be made. Also, more detailed evacuation models can be used that include the 2D road network, traffic bottlenecks and individual behavior (Lumbroso and Tagg 2011; Uno and Kashiyama 2008; Takabatake et al. 2017).

Other uncertainties can be associated with the selection of tsunami levels and the modeling of the flood scenarios. The tsunami levels are based on the distribution curve, and depending on the distribution curve chosen, the corresponding incoming wave height for a $1 / 1000$ year tsunami can differ by around $10 \mathrm{~m}$. Note also that in the present work the area of subduction failure was taken as constant, and as the 2011 Tohoku Earthquake showed, level 2 events can mobilize large section of the fault, even if there is no historical evidence for it. However, since extreme tsunami scenarios have a small contribution to risk, the large difference in incoming tsunami heights for less-frequent tsunamis are not weighed highly in this study. Nevertheless, the authors strongly recommend that any evacuation buildings should be designed with the most onerous wave heights in mind, and thus recommend adding at least another $10 \mathrm{~m}$ to the design level of these buildings as a factor of safety. The 1D run-up model is obviously also limited in its ability to provide answers for the entire city, and flood scenarios can be improved by using 2D models, which should include spatially varying hydraulic roughness. In this sense, the present paper is only a proof of concept and should be followed by a more detailed appraisal.

The optimized communication measure which was considered in this study is based on the wireless receivers which were seen to be successful in Minamisanriku (Fraser et al. 2012). However, this system is old-fashioned compared to a new one being proposed by the Cabinet Office, which is expected to be implemented in Japan by 2019 (Cabinet Office 2016). This project is called the SIP (cross-ministerial Strategic Innovation Promotion program) project and aims to incorporate applications in smart phones to improve the effectiveness of disaster warning systems for all of Japan. It is expected to be cheaper and more effective than the past systems, and thus the costs used in the paper would likely decrease (though it should be noted that using higher costs results in a conservative answer).

\subsection{Choice of preliminary risk-reduction solution}

In this section, the choice of a preliminary risk-reduction solution for Kamakura is discussed based on the results of the study, and assumptions are made for possible intervention demands that can be posed by different stakeholders. Determining the most favorable option is very difficult as there are presently no guidelines for the required safety level. Moreover, making the choice based on the CBA, where fatalities are the major source of costs, depends on the moral judgment on assigning an acceptable cost to the amount of fatalities in case of a tsunami.

The choice for the most favorable strategy among the options considered will be made by weighing the results of the risk assessment methods. This type of approach is conducted in the Netherlands as it is presumed to assess the safety from different perspectives 
(Jonkman and Schweckendiek 2015). Based on the CBA, the most favorable strategy is different from the one which would be chosen if the individual and societal risk were taken into account. The CBA favors the solution with the lowest total cost and the maximum cost-benefit ratio, while taking into account individual and societal risk favors the solution with the lowest risk levels.

In this study, it appeared that the costs to protect Kamakura are high, as simulations using $\mathrm{N}$-waves indicate that a tsunami would still overflow floodwalls due to reflection. However, the relationship between the tsunami height, reflection and the resulting water overflow past a structure is still not well understood, and the authors will seek to clarify this phenomenon in future work. At the same time, loss of life can be significantly reduced by means of better warning. With all of these considerations in mind, the most favorable strategy among the options considered for Kamakura seems to be improving evacuation through the construction of vertical evacuation buildings and optimized communication strategies. The reduction in total cost is estimated to be $€ 4.36$ billion, and the resulting individual and societal risk are in a lower range (in the $10^{-4}$ order of magnitude, compared to other results). The feasibility and ease of implementation of this measure is also expected to be more appealing to policymakers and local authorities than the construction of a large seawall or dike. However, the authors wish to emphasize that many simplifications and assumptions have been made in the present work, and several improvements to the methodology are possible. However, this preliminary solution and its approach are expected to help guide future more detailed assessments of possible interventions to reduce tsunami risk in Kamakura.

\subsection{Options for using a risk-based approach in the tsunami flood management in Japan}

The application of the risk-based approach to tsunami flood management conducted in this study illustrates that this method can present an approximation of the potential risk from tsunamis and possible risk-reduction measures, and that it is possible to carry out a tsunami risk assessment.

A tsunami risk assessment could assist the development of a risk-reduction strategy in which the most effective combination of interventions is investigated. Synergistic combinations between various interventions could be derived (protection, landfills and land use changes, emergency management), also by considering both the economic risk and risk to life. It should be noted that interventions in the areas that were affected by the 2011 tsunami have already been implemented (Esteban et al. 2015). Nevertheless, the approach presented in this paper could be applied for the investigation of risk-reduction strategies in other tsunami-prone areas in Japan and other countries.

Finally, an acceptable risk level for the individual and societal risk is not defined for tsunamis in Japan. This would require the adoption of the risk-based concepts and political decision making on acceptable risk levels. Thus, for these levels to be defined for tsunamis in Japan, more research must be done to understand the levels of acceptable risk defined for other hazards in Japan, such as nuclear reactors. In the current practice in Japan, a design level of tsunamis is chosen based on historical events. In many regions, coastal protection facilities are designed base on so-called Level 1 tsunami, which corresponds to tsunami which has occurred in history with a return period in the order of a hundred years or so (Sato 2015; Shibayama et al. 2013). Additionally, a level 2 tsunami is considered, which would represent an event with a return period of one in several thousand years, and evacuation plans should be designed with this event in mind. Since this design philosophy 
is to some degree based on the notions of probability and risk, it is recommended to further compare the two approaches (full probabilistic risk assessment vs. level 1 and 2 philosophy) in future work.

Finally, the authors want to point out that assigning an economic value of human life to fatalities does not seem common in Japan although MLIT (2009) have specified a value for civil projects. Assigning such a "value of human life" is a sensitive issue, and it is the choice of decisionmakers whether this should be done. The authors do not necessarily believe that assigning such a value is the best way. The inclusion of an economic value of human life in this paper was done for illustration purposes and to come to an assessment of the cost effectiveness of interventions. Alternatively, instead of assigning an economic value to human life, separate decision criteria could be assigned to the risk to human life, such as the individual and societal risk concepts introduced in this paper.

\section{Conclusion}

A risk assessment framework for tsunamis was developed, and the framework was then applied to evaluate a case study of the city of Kamakura. The results indicate that a tsunami event in this area can expose over half of the total population of Kamakura to flooding, resulting in thousands of casualties. For all tsunami levels which have been simulated, $90 \%$ of total damage costs are a result of fatalities. Based on the quantitative analysis of the flood risk, the results indicate that the cost-benefit ratio is maximized and the societal risk levels are low, in other words closer to the TAW line rather than that of the baseline condition, for evacuation improvements. The dike heightening intervention had a limit to the reduction in risk it could accomplish. This flood risk assessment for tsunamis can be applicable to other tsunami-prone areas.

The results presented are based on a simplified framework for flood risk assessment. For a more elaborate risk assessment, improvements can be made to each step. The most important step in the framework is the determination of the tsunami return period, including the use of bootstrapping methods in the fit of the tsunami exceedance curve. This influences all of the following steps in the framework and is also the most difficult to determine. A more complete assessment of the various earthquakes for multiple troughs, locations and magnitudes is recommended to come to a more complete characterization of the range and return periods of possible tsunami waves at Kamakura. Further improvement can be made in this step by employing a $2 \mathrm{D}$ approach in flood modeling and evacuation modeling, with the inclusion of spatially distributed data. 2D simulations for the tsunami run-up would highly improve the accuracy of the flood mapping, thus resulting in a better approximation of the potential consequences. Another improvement would be to add parametric dependencies among different variables such as earthquake magnitude and deflection height. These improvements can be made to reduce the uncertainty which exists in this step. Nevertheless, the framework developed aims to give a first approximation for risk-reducing design.

Based on these results, further investigation of the possibilities for risk-reduction interventions for Kamakura is recommended to prepare for possible future tsunamis. The results also indicate that improvements to the evacuation measures should be recommended over hard structures such as sea walls and dikes. Therefore, information regarding the structural safety and elevation of evacuation areas, and the space available at these areas will be of importance in more elaborate studies. 
For a more complete evaluation of tsunami risk in Kamakura, improvements need to be made not only for the determination of the tsunami return period, but also in the assessment of the consequences. The population at risk in this study only considers the local population, though the large number of tourists present could also influence the results. Moreover, the population and housing distribution is assumed to be uniform. In reality, however, the houses are more densely built near the coast, which could result in a larger number of casualties; thus, improvements in spatial distributions can be expected to produce more accurate results. Finally, the evacuation model uses deterministic values to portray human behavior. The model can be improved by obtaining realistic calibrated values variables, such as the evacuation behavior. Overall, the results indicate the necessity for further discussion on how to reduce the risk or vulnerability of a tsunami-prone city. The results presented in this study aim to provide the input information to discuss improvements in the tsunami risk management.

Open Access This article is distributed under the terms of the Creative Commons Attribution 4.0 International License (http://creativecommons.org/licenses/by/4.0/), which permits unrestricted use, distribution, and reproduction in any medium, provided you give appropriate credit to the original author(s) and the source, provide a link to the Creative Commons license, and indicate if changes were made.

\section{References}

Cabinet Office (2016) Cross-ministerial strategic innovation promotion program - increase the resilience against disasters (translated from Japanese). Retrieved from http://www8.cao.go.jp/cstp/gaiyo/sip/

Carey N (2005) Establishing pedestrian walking speeds. Project Report, Portland State University, ITE Student Chapter

Carlos-Arce RS, Onuki M, Esteban M, Shibayama T (2017) Risk awareness and intended tsunami evacuation behaviour of international tourists in Kamakura City, Japan. Int J Disast Risk Reduct 23:178-192

Central Disaster Management Council of Japan (2013) Disaster management in Japan (translated from Japanese). Retrieved from http://www.bousai.go.jp/jishin/syuto/taisaku_wg/index.html

Daiwa House Corporation (2015) Tsunami emergency evacuation space for roof tops "W-ev Tower" (translated from Japanese). http://www.daiwahouse.co.jp/release/20150617103646.html. Accessed 28 June 2016

de Neufville R (1990) Applied systems analysis: engineering planning and technology management. McGraw-Hill Publishing Company, Maidenherd

Esteban M, Onuki M, Ikeda I, Akiyama T (2015) Reconstruction following the 2011 Tohoku earthquake tsunami: case study of Otsuchi Town in Iwate Prefecture, Japan. In: Esteban M, Takagi H, Shibayama $\mathrm{T}$ (eds) Handbook of coastal disaster mitigation for engineers and planners. Butterworth-Heinemann (Elseview), Oxford

Fraser S, Matsuo I, Leonard G, Murakami H (2012) Tsunami evacuation: lessons from the Great East Japan earthquake and tsunami of March 11th 2011. Technical Report GNS Science Report 2012/17

GEBCO (2016) General Bathymetric chart of the oceans, bathymetric data of Sagami Bay. Retrieved from http://www.gebco.net/data_and_products/gridded_bathymetry_data/. Accessed 20 Feb 2016

Goto Y, Affan M, Nurdin AY, Yuliana DK, Ardiansyah M (2012) Tsunami evacuation simulation for disaster education and city planning. J Disaster Res 7(1):92-101

Hall JW, Dawson RJ, Sayers PB, Rosu C, Chatterton JB, Deakin R (2003) A methodology for national-scale flood risk assessment. In: Proceedings of the ICE—water and maritime engineering, 01 Sept 2003, vol 156 , No. 3, pp 235-247

IPET (2009) Final report of the Interagency performance evaluation task force (IPET). Volume VIIIengineering and operational risk and reliability analysis. Report, USACE

Ishii H (2017) The research of comparing calculation characteristics between 2D tsunami simulation and 3D tsunami simulation in real terrain (Bachelor Thesis, submitted). Waseda University, Tokyo

Jayaratne MPR, Premaratne B, Adewale A, Mikami T, Matsuba S, Shibayama T, Esteban M, Nistor I (2016) Failure mechanisms and local scour at coastal structures induced by tsunami. Coast Eng J 58(4):1640017. doi:10.1152/S0578563416400179 
Jiabi X, Sayers P, Dongya S, Hanghui Z (2013) Broad-scale reliability analysis of the flood defence infrastructure within the Taihu Basin, China. J Flood Risk Manag 6(2013):42-56

Jongejan RB, Maaskant B (2015) Quantifying flood risks in the Netherlands. Risk Anal 35(2):252-264

Jonkman SN, Penning-Rowsell E (2008) Human instability in flood flows. J Am Water Resour Assoc 44(5):1208-1218

Jonkman SN, Schweckendiek T (2015) Flood defenses lecture notes. Delft University of Technology, Delft

Jonkman SN, Vrijling JK, Kok M (2008) Flood risk assessment in the Netherlands: a case study for dike ring South Holland. Risk Anal 28(5):1357-1373

Jonkman SN, Jongejan RB, Maaskant B (2011) The Use of Individual and Societal Risk Criteria within the Dutch Flood Safety Policy-Nationwide Estimates of Societal Risk and Policy Applications. Risk Anal 31(2):282-300

Kamakura City Office (2016) Expected Tsunami inundation map for Kamakura city, number of tourist and beach visitors, Real state and land market prices. http://www.city.kamakura.kanagawa.jp/. Accessed 12 Feb 2016

Kanagawa Prefectural Government (2016) Statistics on cities in Kanagawa, inundation maps for historical tsunamis. http://www.pref.kanagawa.jp/. Accessed 12 Feb 2016

Kind JM (2014) Economically efficient flood protection standards for the Netherlands. J Flood Risk Manag 7:103-117

Lumbroso DM, Tagg AF (2011) Evacuation and loss of life modelling to enhance emergency response. In: Proceedings of the international symposium on urban flood risk management, 21-23 September, Graz, Austria

Mas E, Suppasri A, Imamura F, Koshimura S (2012) Agent-based Simulation of the 2011 Great East Japan Earthquake/Tsunami Evacuation: an Intergrated Model of Tsunami Inundation and Evacuation. J Nat Disaster Sci 34(1):41-57

Mikami T, Shibayama T, Esteban M, Matsumaru R (2012) Field Survey of the 2011 Tohoku Earthquake and Tsunami in Miyagi and Fukushima Prefectures. Coast Eng J (CEJ) 54(1):1-26

Ministry of Land, Infrastructure, Transport and Tourism (MLIT) (2009) Technical guidelines to conduct cost-benefit analysis to evaluate communal projects (Translated from Japanese). Retrieved from http:// www.mlit.go.jp/tec/hyouka/public/090601/0906012.html

Mori N, Takahashi T, Yasuda T, Yanagisawa H (2011) Survey of 2011 Tohoku earthquake tsunami inundation and run-up. Geophys Res Lett 38(18):6-11

Pistrika AK, Jonkman SN (2010) Damage to residential buildings due to flooding of New Orleans after hurricane Katrina. Nat Hazards 54(2):413-434

Sato S (2015) Characteristics of the 2011 Tohoku Tsunami and introduction of two level tsunamis for tsunami disaster mitigation. Proc Jpn Acad Ser B Phys Biol Sci 91(6):262-272

Shibayama T, Esteban M, Nistor I, Takagi H, Thao ND, Matsumaru R, Mikami T, Aranguiz R, Jayaratne R, Ohira K (2013) Classification of Tsunami and Evacuation Areas. Nat Hazards 67(2):365-386

Strunz G, Post J, Zosseder K, Wegscheider S, Mück M, Riedlinger T, Mehl H, Dech S, Birkmann J, Gebert N, Harjano H, Answar HZ et al (2011) Tsunami risk assessment in Indonesia. Nat Hazards Earth Syst Sci 11:67-82

Takabatake T, Shibayama T, Esteban M, Hamano G (2017) Simulated tsunami evacuation behavior of local residents and visitors in Kamakura, Japan. Int J Disaster Risk Reduct 23:1-14

The Headquarters for Earthquake Research Promotion (2016) Information on historical earthquakes along the Sagami Trough (translated from Japanese). Retrieved from http://www.jishin.go.jp/main/ yosokuchizu/kaiko/k_sagami.htm

Tsimopoulou V, Jonkman SN, Kolen B, Maaskant B, Mori N, Yasuda T (2012) A multi-layered safety perspective on the tsunami disaster in Tohoku, Japan. Flood Risk 2012 Conference (Fujita 2011), pp 1-10

Uno K, Kashiyama K (2008) Development of Simulation System for the Disaster Evacuation Based on Multi-Agent Model Using GIS. Tsinghua Sci Techonol 13(Supplement 1):348-353

USGS (2016) United States Geological Survey, Topography data (Landsat, GMTED2010). Accessed 20 Feb 2016

Van Mai C (2010) Probabilistic design of coastal flood defences in Vietnam (doctoral dissertation). Delft University of Technology, Delft

Vrijling JK, Van Hengel W, Houben RJ (1998) Acceptable risk as a basis for design. Reliab Eng Syst Saf 59(1):141-150

Vrijling JK, van Gelder PHAJM (2002) Probabilistic Design in Hydraulic Engineering: CT5310 (F30). TU Delft 
Yamao S, Esteban M, Yun NY, Mikami T, Shibayama T (2015) Estimation of the current risk to human damage life posed by future tsunamis in Japan. In: Handbook of coastal disaster mitigation for engineers and planners. Elsevier Inc., pp 257-275

Yun N-Y, Hamada M (2012) Evacuation Behaviors in the 2011 Great Eastern Japan Earthquake. J Disaster Res 7(7):458-467

Zijlema M, Stelling G, Smit P (2011) SWASH: an operational public domain code for simulating wave fields and rapidly varied flows in coastal waters. Coast Eng 58(10):992-1012 